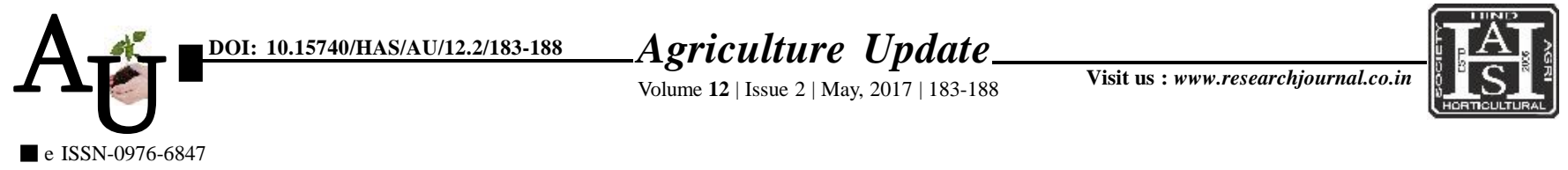

\title{
Research ARticle: Information processing behaviour of the pea growers in Kota region of Rajasthan
}

\section{N.R. MEENA, F.L. SHARMA, R.A. KAUSHIK AND PREVESH CHOUHAN}

Article Chronicle: Received : 01.02.2017;

Revised : 22.02.2017; Accepted : 03.03.2017

\section{KeY WoRDS:}

Pea growers, Vegetable crop, Information processing behaviour
SUMMARY : Findings revealed that out of 200 respondents, 45.50 per cent respondents had low information processing behaviour and 31.50 per cent farmers having medium level of information processing behaviour. Whereas, only 23.00 per cent respondents were observed in high information processing behaviour group. Results further revealed that 51.00 and 40.00 per cent marginal and small farmers, respectively were in the low information processing behaviour group. Likewise, 28.00 and 35.00 per cent marginal and small farmers had medium information processing behaviour about improved pea cultivation practices, respectively. Whereas, 21.00 per cent marginal farmers and 25.00 per cent small farmers were found in high information processing behaviour group about pea production technology. It was noted that among the selected information processing modes, information evaluation methods were used upto greatest extent by the pea growers with MPS 60.15. These were followed by information transfer methods with MPS 44.60. However, information storage methods with 40.11 MPS were least used information processing methods by the pea growers. (iii) Findings indicated that there was significant difference in information processing behaviour between marginal and small farmers about pea cultivation technology. The mean value further indicates that small farmers had higher information processing behaviour than marginal farmers about pea cultivation technology.

How to cite this article : Meena, N.R., Sharma, F.L., Kaushik, R.A. and Chouhan, Prevesh (2017). Information processing behaviour of the pea growers in Kota region of Rajasthan. Agric. Update, 12(2): 183-188; DOI : 10.15740/HAS/AU/12.2/183-188.
Author for correspondence :

\section{N.R. MEENA}

Lt. Moolchand Meena Agriculture College, Lalsot, DAUSA (RAJASTHAN) INDIA

See end of the article for authors' affiliations 